\title{
Health concerns prompt US review of exotic-pet trade
}

\section{Erika Check, Washington}

For years, biologists have railed against the US\$6-billion international wildlife trade, claiming that it has driven a long list of species to the brink of extinction. Now the US government seems to be paying attention to such protests - but not because of any newfound concern for animal welfare.

Instead, US officials are worried about diseases such as severe acute respiratory syndrome (SARS) and monkeypox, which caused epidemics last year when they jumped from animals to people. Conservation groups have been arguing that the animal trade is to blame for such epidemics and they seem to be gaining the ear of the government.

The latest call came on 14 January, when the New Yorkbased group Wildlife Trust convened biologists and ecologists from ten countries in

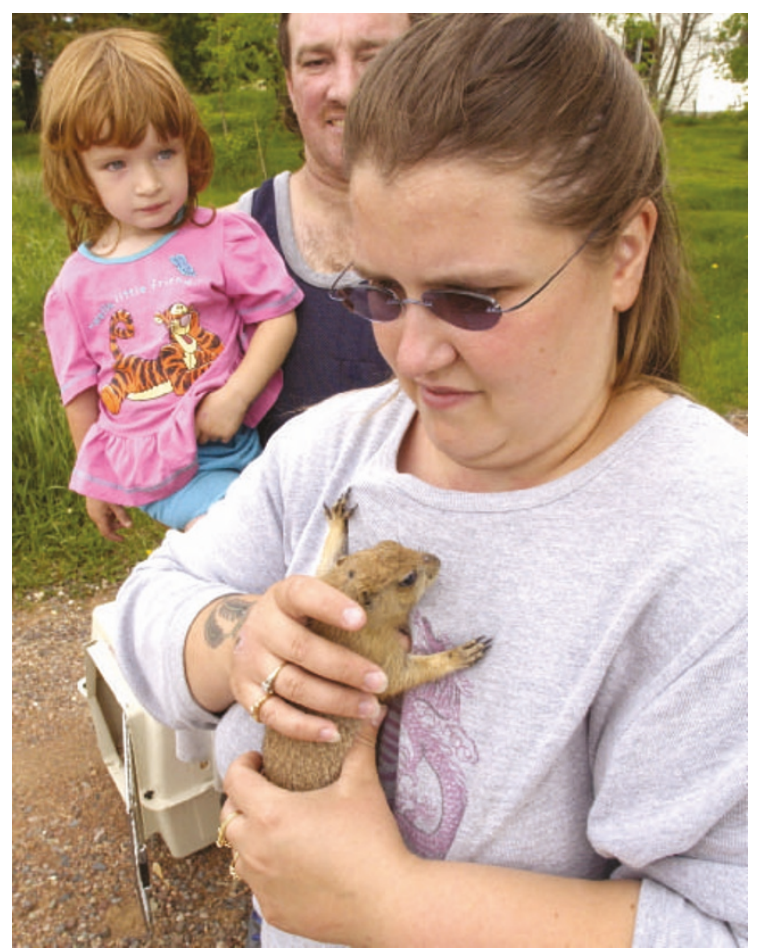

Caught out: this US family found themselves in quarantine last summer after one of their pet prairie dogs gave them monkeypox.
Bangalore, India. The scientists issued a declaration calling for "an urgent reassessment of current wildlife trade practices”.

Last summer, a coalition of US epidemiologists and veterinarians said that the federal government should expand an order that restricted the importation of rats and prairie dogs into the United States. The animals were responsible for an outbreak of monkeypox that infected 40 people in the midwest last summer.

"To protect public health, this order should be permanently sustained and expanded to restrict the movement of exotic wildlife with potential adverse impact on public health," the Council of State and Territorial Epidemiologists and the National Association of State Public Health Veterinarians wrote in a letter to government agencies including the Centers for Disease Control and Prevention (CDC) in Atlanta, Georgia.

Now there are signs that such arguments are hitting home. On 13 January, the US health department declared the country off-limits to civets in a precaution against an outbreak of SARS, the flu-like illness first reported in China last February. Nobody has yet proved that the animals were the source of the SARS epidemic, but scientists have found that civets on sale in Chinese markets harbour viruses that are very similar to those that cause SARS. US health officials say that since the civet market is not large in the United States only 50 are imported everyyear - this limited evidence convinced them to enact a ban. And they say that they are looking for a more widespread approach to the problem of animalborne, or zoonotic, diseases.

"There's been a lot of increased discussion from federal agencies and independent groups to see what can be done to reduce the risk of importing zoonotic disease into this country," says Paul Arguin, a specialist in animal-borne diseases at the CDC. Arguin says that the CDC has been talking with the public-health veterinarians' group on ways to address this threat. "It's fair to say that the $\mathrm{CDC}$ is in support of increased regulation of the exotic-pet trade," he says.

Mary Pearl, president of the Wildlife Trust, says that such regulation is overdue. For a start, she says, governments should use better quarantine and surveillance methods for animals coming into the country, and could give more funding to enforcement agencies that are supposed to police the illegal wildlife trade.

"They've been rapidly closing the barn door after the horse has bolted," Pearl says. "It would make more sense to have a rational set of policies that requires adequate surveillance of the wildlife trade, because there simply are not enough safeguards to protect public health."

\section{Telepathic charm seduces audience at paranormal debate}

John Whitfield, London

Scientists tend to steer clear of public debates with advocates of the paranormal. And judging from the response of a London audience to a rare example of such a head-to-head conflict last week, they are wise to do so.

Lewis Wolpert, a developmental biologist at University College London, made the case against the existence of telepathy at a debate at the Royal Society of Arts (RSA) in London on 15 January. Rupert Sheldrake, a former biochemist and plant physiologist at the University of Cambridge who has taken up parapsychology, argued in its favour. And most of the 200-strong audience seemed to agree with him.

Wolpert is one of Britain's bestknown public spokesmen for science. But few members of the audience seemed to be swayed by his arguments.

Sheldrake, who moved beyond the scientific pale in the early 1980 s by claiming that ideas and forms can spread by a mysterious force he called morphic resonance, kicked off the debate.

He presented the results of tests of extrasensory perception, together with his own research on whether people know who is going to phone or e-mail them, on whether dogs know when their owners are coming home, and on the allegedly telepathic bond between a New York woman and her parrot. "Billions of perfectly rational people believe that they have had these experiences," he said.

Wolpert countered that telepathy was "pathological science", based on tiny, unrepeatable effects backed up by fantastic theories and an ad hoc response to criticism. "The blunt fact is that there's no persuasive evidence for it," he said. "An open mind is a very bad thing everything falls out."

For Ann Blaber, who works in children's music and was undecided on the subject, Sheldrake was the more convincing. "You can't just dismiss all the evidence for telepathy out of hand," she said. Her view was reflected by many in the audience, who variously accused Wolpert of "not knowing the evidence" and being "unscientific".

In staging the debate, the RSA joins a growing list of London organizations taking a novel approach to science communication (see Nature 426, 6; 2003). "We want to provide a platform for controversial subjects," says Liz Winder, head of lectures at the RSA. 